\title{
Social Intelligence and Communication Competence: Predictors of Students' Intercultural Sensitivity
}

\author{
Takwa Bosuwon ${ }^{1}$ \\ ${ }^{1}$ School of Humanities and Applied Arts, University of the Thai Chamber of Commerce, Thailand \\ Correspondence: Takwa Bosuwon, School of Humanities and Applied Arts, University of the Thai Chamber of \\ Commerce, Bangkok, 10400, Thailand. Tel: 66-2697-6411. E-mail: takwa_bosuwon@utcc.ac.th
}

Received: December 19, 2016

Accepted: January 19, 2017 Online Published: January 22, 2017

doi: 10.5539/elt.v10n2p136

URL: http://dx.doi.org/10.5539/elt.v10n2p136

\begin{abstract}
This study investigated the level of intercultural sensitivity of foreign international undergraduates and its possible predictors. Sample participants included 269 foreign international undergraduates of both government and private universities in Thailand. The research instrument was the three-page survey constructed questionnaire based on the combination of three self-evaluation scales: Chen and Starosta's (2000) Intercultural Sensitivity Scale (ISS), McCroskey and McCroskey's (1988) Self-Perceived Communication Competence Scale (SPCC), and Silvera et al's (2001) Tromso Social Intelligence Scale (TSIS). From the pilot test, the instrument's internal consistency was .789. Data collected were analyzed by using Descriptive Statistics (SPSS for Windows), Pearson product-moment Correlations, Independent-sample t-test, F-test (ANOVA), and Multiple Regression Analysis. The findings showed that the average level of intercultural sensitivity of the participants was at a high level $(\mathrm{X}=4.3)$ with nationality and intercultural experience as significant factors. It was also found that both self-perceived communication competence and social intelligence were statistically significant predictors of intercultural sensitivity.
\end{abstract}

Keywords: intercultural sensitivity, communication competence, social intelligence, international undergraduate

\section{Introduction}

\subsection{Intercultural Communication Competence Needed in Global Business}

Intercultural communication skills have played a crucial role when there has been a force for cultural de-globalization or cultural pluralism in an increasingly multi-polar world economy (Hooker, 2008). Today, businesses are conducted across borders. Therefore, economic success of each business sector, organization, or country increasingly depends on the ability of employees or officials to display competent intercultural communication behaviors with individuals from other cultures (Lustig \& Koester, 2003; Varner \& Beamer, 2010; Franko, 2012). Developing intercultural competence is; therefore, regarded as part of qualifying professionally (Korhonen, 2004; Mao, 2010) especially for leadership in the global workplace.

\subsection{Intercultural Sensitivity Boosting Intercultural Communication Competence}

Intercultural sensitivity is one of the three dimensions of intercultural communication competence: intercultural awareness, intercultural sensitivity, and intercultural adroitness (Chen \& Starosta, 1996). Each of these dimensions contains a set of components. Intercultural sensitivity is the affective dimension of intercultural communication competence that refers to 'the emotional desire of a person to acknowledge, appreciate, and accept cultural differences' (Fritz et al., 2002). The intercultural sensitivity dimension includes six components: self-esteem, self-monitoring, empathy, open-mindedness, nonjudgmental, and social relaxation. All these components enable "an individual to develop a positive emotion towards understanding and appreciating cultural differences that promotes appropriate and effective behavior in intercultural communication" (Chen \& Starosta, 1997a).

Intercultural communication becomes competent when it consists of all three basic components as mentioned earlier. Intercultural sensitivity is an affective process. Intercultural awareness is a cognitive process, and intercultural adroitness is a behavioral process (Chen \& Starosta, 1998). Therefore, a lack of intercultural sensitivity causes incompetent intercultural communication or even failure. Research on intercultural communication competence and intercultural sensitivity shows significant correlation. That is, the more 
intercultural sensitivity an individual possesses, the more interculturally competent he/she can be (Klak \& Martin, 2003; Goby, 2007; Straffon, 2003; Olson \& Kroeger, 2001).

Intercultural sensitivity is, therefore, considered a crucial factor that has received considerable attention in the past decades (Chen \& Starosta, 1997b; Rahim, 1983; Triandis, 2006). It was found that high intercultural sensitivity was associated with high intercultural competence (Mendenhall \& Oddou, 1985; Black \& Mendenhall, 1990; Chen \& Starosta, 2000; Klak \& Martin, 2003). Moreover, intercultural sensitivity can be shaped by many factors (Dong et al., 2008).

\subsection{Research Objectives}

This study aimed to investigate the intercultural sensitivity of foreign international undergraduates and to what extent self-perceived communication competence and social intelligence can significantly predict intercultural sensitivity.

\section{Method}

\subsection{Sample}

Based on convenience sampling, the participants of the study were 269 foreign international undergraduates of both government and private universities in Thailand. These students from 39 countries had different demographic factors.

\subsection{Instrument}

An English-version survey questionnaire was constructed based on the combination of three scales to test levels of intercultural sensitivity among foreign international undergraduates, self-perceived communication competence, and their social intelligence. This 69-item questionnaire consisted of 4 sections including a checklist asking about the respondents' demographic information and the three scales, including:

\subsubsection{Chen and Starosta's (2000) Intercultural Sensitivity Scale or ISS}

The ISS covers 24 statements (120 points) on self-reported intercultural sensitivity. It was designed based on five labeled factors: (1) interaction engagement (e.g. "I enjoy interacting with people from different cultures"), (2) respect for cultural differences (e.g. "I think people from other cultures are narrow-minded"), (3) interaction confidence (e.g. "I am pretty sure of myself in interacting with people from different cultures"), (4) interaction enjoyment (e.g. "I get upset easily when interacting with people from different cultures"), and (5) interaction attentiveness (e.g. I am very observant when interacting with people from different cultures").

This scale has proven to have high reliability and validity, and has been used in a number of studies (Fritz et al., 2002; Peng et al., 2005; Yu \& Chen, 2008; Park, 2013).

\subsubsection{McCroskey and McCroskey's (1988) Self-Perceived Communication Competence Scale or SPCC}

The SPCC was developed by McCroskey \& McCroskey (1988). The scale assesses how competent people feel they are in various communication contexts and with various types of receivers, although it is not a measure of actual communication competence. The SPCC scale has generated good alpha reliability estimates (above .85) and has a strong face validity as well as substantial predictive validity in terms of self-perceptions. The SPCC scale is composed of 12 items reflecting four communication contexts--public speaking, talking in a large meeting, talking in a small group, and talking in a dyad--and three common types of receivers--strangers, acquaintances, and friends.

\subsubsection{Silvera, Martinussen, and Dahl's (2001) Tromso Social Intelligence Scale (TSIS)}

The TSIS consists of 21 items with 3 subscales including SP: social information processing (e.g. I can easily understand social situations.), SS: social skills (e.g. I am successful in establishing new relationships.), and SA: social awareness (e.g. I am often surprised how other people react to my actions.) This seven-point scale questionnaire's internal validities of SP, SS, and SA were $0.79,0.85$, and 0.72 respectively (Silvera et al, 2001). This is considered an approach to detect social intelligence as a performance characteristic.

The questionnaire was pilot tested with international students who were as demographically similar to the sample as possible. The results of the pilot showed that the overall internal consistency of the instrument was .789 (Intercultural Sensitivity Scale $=.667$, Self-perceived Communication Competence Scale $=.921$, and Social Intelligence Scale $=.623$ ).

\subsection{Data Collection}

Once the consent was granted, 400 copies of the questionnaire were made and then distributed by hand to the 
international undergraduates studying in universities in Bangkok. The participants were told that the survey was voluntary and their information would be completely confidential and anonymous. The questionnaire took approximately 15 minutes for individual participants to complete. Three hundred and four questionnaires were returned. After removing all of the questionnaires with missing responses, there were two hundred and sixty-nine questionnaires available for statistical analysis.

\section{Results}

\subsection{Level of Intercultural Sensitivity and its Five Elements}

The average level of intercultural sensitivity of the participants was at a high level ( $\mathrm{X}=4.3$ or 92.29 out of 120 points). All of the five elements had a positive correlation with the total intercultural sensitivity scores. Interaction engagement and respect for cultural difference had a very high positive correlation: $.809, .804$. Interaction enjoyment had a high positive correlation: .741 and interaction confidence and attentiveness had a moderate positive correlation: .667, .557.

Table 1. Levels of Intercultural Sensitivity

\begin{tabular}{lllll}
\hline Elements of Intercultural Sensitivity & Total Score & Mean score & S.D & $\%$ \\
\hline 1. Interaction engagement & 35 & 26.80 & 3.82 & 76.57 \\
2. Respect for cultural difference & 30 & 24.51 & 4.24 & 81.70 \\
3. Interaction confidence & 25 & 18.30 & 3.07 & 73.20 \\
4. Interaction enjoyment & 15 & 11.63 & 2.57 & 77.53 \\
5. Interaction attentiveness & 15 & 11.05 & 1.98 & 73.67 \\
\hline Total intercultural sensitivity score & 120 & 92.29 & 11.56 & 76.91 \\
\hline
\end{tabular}

\subsection{Level of Intercultural Sensitivity and Demographic Factors}

While gender and school of study did not have any significant effect on the level of intercultural sensitivity, nationality and intercultural experience did more or less have a role to play.

\subsubsection{Nationality}

It was found that American participants' scores were significantly higher than the Chinese scores. According to Table 2, the total intercultural sensitivity scores as well as scores from each intercultural sensitivity factor between the Chinese and the American are significantly different from each other. This means, on average, the American's scores (both total intercultural sensitivity score and each factor score) are higher than the Chinese's. Based on the arbitrary classification (1-24 = very low, 25-48 = low, 49-72 = moderate, 73-96 = high, 97-120 = very high) of intercultural sensitivity levels, it was clearly shown that the American participants had a very high level $(98.02,81.68 \%)$ while the Chinese participants had a high level $(82.40,68.67 \%)$ of intercultural sensitivity.

Table 2. Comparisons between Intercultural Sensitivity Scores of Chinese and American Foreign International Undergraduates

\begin{tabular}{llllll}
\hline Intercultural Sensitivity & $\begin{array}{l}\text { Total } \\
\text { score }\end{array}$ & \multicolumn{2}{l}{$\begin{array}{l}\text { Chinese } \\
(\mathrm{N}=40)\end{array}$} & \multicolumn{3}{c}{$\begin{array}{l}\text { American } \\
(\mathrm{N}=50)\end{array}$} \\
\cline { 3 - 6 } & & score & $\%$ & score & $\%$ \\
\hline 1. Interaction engagement & 35 & 24.27 & 69.34 & 28.96 & 82.74 \\
\hline 2. Respect for cultural differences & 30 & 20.92 & 69.73 & 26.38 & 87.93 \\
\hline 3. Interaction confidence & 25 & 17.02 & 68.08 & 18.44 & 73.76 \\
\hline 4. Interaction enjoyment & 15 & 9.57 & 63.80 & 12.44 & 82.93 \\
\hline 5. Interaction attentiveness & 15 & 10.60 & 70.67 & 11.80 & 78.67 \\
\hline Total intercultural sensitivity score & 120 & 82.40 & 68.67 & 98.02 & 81.68 \\
\hline
\end{tabular}




\subsubsection{Intercultural Experience (Length of Stay in Other Cultures)}

It was found that the intercultural sensitivity scores of those who had less than 1 year or more than 4 years of intercultural experience were significantly higher than the scores of those who had 3-4 years of experience. Table 3 shows the differences among the average intercultural sensitivity score (ISS) of 4 types of exposure to other cultures of international undergraduates: less than 1 year, 1-2 years, 3-4 years, and 5 years onwards.

Table 3. The Differences among the Intercultural Sensitivity Scores based on Intercultural Experience

\begin{tabular}{|c|c|c|c|c|}
\hline Source of variance & SS. & df & MS. & $\mathrm{F}$ \\
\hline \multicolumn{5}{|c|}{ Interaction engagement } \\
\hline Between groups & 259.247 & 3 & 86.416 & $6.259 *$ \\
\hline Within groups & 3658.507 & 265 & 13.806 & \\
\hline Total & 3917.755 & 268 & & \\
\hline \multicolumn{5}{|c|}{ Respect for cultural difference } \\
\hline Between groups & 368.570 & 3 & 122.857 & $7.305^{*}$ \\
\hline Within groups & 4456.635 & 265 & 16.817 & \\
\hline Total & 4825.204 & 268 & & \\
\hline \multicolumn{5}{|c|}{ Interaction confidence } \\
\hline Between groups & 68.714 & 3 & 22.905 & 2.474 \\
\hline Within groups & 2453.494 & 265 & 9.258 & \\
\hline Total & 2522.208 & 268 & & \\
\hline \multicolumn{5}{|c|}{ Interaction enjoyment } \\
\hline Between groups & 47.461 & 3 & 15.820 & 2.425 \\
\hline Within groups & 1729.104 & 265 & 6.525 & \\
\hline Total & 1776.565 & 268 & & \\
\hline \multicolumn{5}{|c|}{ Interaction attentiveness } \\
\hline Between groups & 26.026 & 3 & 8.675 & 2.240 \\
\hline Within groups & 1026.346 & 265 & 3.873 & \\
\hline Total & 1052.372 & 268 & & \\
\hline \multicolumn{5}{|c|}{ Intercultural sensitivity } \\
\hline Between groups & 2261.761 & 3 & 753.920 & $5.950 *$ \\
\hline Within groups & 33579.198 & 265 & 126.714 & \\
\hline Total & 35840.959 & 268 & & \\
\hline
\end{tabular}

$* \mathrm{p}<0.05$.

Table 3 reveals that, on average, the total scores of the intercultural sensitivity as well as sub scores of the first two elements (interaction engagement and respect for cultural difference) of the 4 group types having different intercultural experience are significantly different $(\alpha=0.05)$. This means that, on average, their scores are not the same, so post hoc tests were performed to test the differences of their intercultural sensitivity scores.

Table 4. Results of the Post Hoc (Scheffe) Test on the total intercultural sensitivity

\begin{tabular}{llll}
\hline $\begin{array}{l}\text { Experience abroad } \\
\text { (Length of stay abroad) }\end{array}$ & $\mathrm{N}$ & Subset for alpha $=0.05$ & \\
\cline { 3 - 4 } & & 1 & 2 \\
\hline 3-4 years & 37 & 87.4865 & \\
\hline
\end{tabular}




\begin{tabular}{llll}
\hline $1-2$ years & 89 & 90.1124 & 90.1124 \\
Less than 1 year & 96 & & 94.5833 \\
5 years or more & 47 & .670 & 95.4894 \\
Sig. & & .091 \\
\hline
\end{tabular}

Table 4 shows that the intercultural sensitivity mean score of participants with 3-4 years of exposure to other cultures was not significantly different from those with 1-2 years, but significantly different from those with less than 1 year and more than 4 years.

\subsection{Possible Predictive Factors of Intercultural Sensitivity}

The study has proved that the level of intercultural sensitivity of international undergraduates can be predicted by both self-perceived communication competence (R square: .296) and social intelligence (R square: .428). In other words, communication competence had $29.6 \%$ predictive ability on intercultural sensitivity while social intelligence had $42.8 \%$ predictive ability on intercultural sensitivity.

\subsubsection{Self-perceived Communication Competence}

Table 5 below shows that F-value (.000) was statistically significant (typically $\mathrm{p}<.05$ ). This signifies that the predictor (communication competence) accurately predicted the outcome variable or the scores of intercultural sensitivity and that there was a significant relationship between the predictor and the dependent variable. The coefficient force was .754 . So, for every point increase in communication competence score, a 0.75 point increase in intercultural sensitivity score was predicted, keeping all other variables constant. The $\mathrm{R}$ square was .296 . This means that communication competence had $29.6 \%$ predictive ability on intercultural sensitivity.

Table 5. Self-perceived Communication Competence as a Possible Intercultural Sensitivity Predictor Model Summary

\begin{tabular}{lllll}
\hline Model & R & R Square & Adjusted R Square & Std. Error pf the Estimate \\
\hline 1 & $.544^{\mathrm{a}}$ & .296 & .293 & 9.72408 \\
\hline
\end{tabular}

\begin{tabular}{lllll}
\hline Changes Statistics & \multicolumn{5}{l}{} \\
\hline R Square Change & F Change & df1 & df2 & Sig. F Change \\
\hline .296 & 112.038 & 1 & 267 & .000 \\
\hline
\end{tabular}

a. Predictors: (Constant), Communication Competence

ANOVA $^{\mathrm{b}}$

\begin{tabular}{llllll}
\hline Model & Sum of Squares & df & Mean Square & F & Sig. \\
\hline 1 Regression & 10594.057 & 1 & 10594.057 & 112.038 & $.000^{\mathrm{a}}$ \\
Residual & 25246.902 & 267 & 94.558 & & \\
Total & 35840.959 & 268 & & & \\
\hline
\end{tabular}

a. Predictors: (Constant), Communication Competence

b. Dependent Variable: Intercultural sensitivity

\section{Coefficients $^{\mathrm{a}}$}

\begin{tabular}{llllll}
\hline Model & \multicolumn{2}{l}{ Unstandardized Coefficients } & $\begin{array}{l}\text { Standardized } \\
\text { Coefficients }\end{array}$ & t & Sig. \\
\cline { 2 - 4 } & $\mathrm{B}$ & Std. Error & Beta & \\
\hline 1 (Constant) & 58.271 & 3.268 & .544 & 17.831 & .000 \\
Communication Competence & .754 & .071 & & 10.585 & .000 \\
\hline
\end{tabular}

a. Dependent Variable: Intercultural Sensitivity. 


\subsubsection{Social intelligence}

Table 6 shows that F-value (.000) was statistically significant (typically $\mathrm{p}<.05$ ). This signifies that the predictor (self-perceived communication competence) accurately predicted the outcome variable or the scores of intercultural sensitivity and that there was a significant relationship between the predictor and the dependent variable. The coefficient force was .804 . So, for every point increase in social intelligence score, a 0.80 point increase in intercultural sensitivity score was predicted, keeping all other variables constant. The $\mathrm{R}$ square was .428 . This means that social intelligence had $42.8 \%$ predictive ability on intercultural sensitivity.

Table 6. Social Intelligence as a possible intercultural sensitivity predictor

Model Summary

\begin{tabular}{lllll}
\hline Model & $\mathrm{R}$ & R Square & Adjusted R Square & Std. Error pf the Estimate \\
\hline 1 & $.654^{\mathrm{a}}$ & .428 & .426 & 8.76231 \\
\hline
\end{tabular}

\begin{tabular}{lllll}
\hline Changes Statistics & & & \\
\hline R Square Change & F Change & df1 & df2 & Sig. F Change \\
\hline .428 & 199.812 & 1 & 267 & .000 \\
\hline
\end{tabular}

a. Predictors: (Constant), Social Intelligence.

\begin{tabular}{llllll} 
ANOVA $^{\mathrm{b}}$ & & & & \\
\hline Model & Sum of Squares & df & Mean Square & F & Sig. \\
\hline 1 Regression & 15341.203 & 1 & 10594.057 & 15341.203 & $.000^{\mathrm{a}}$ \\
Residual & 20499.756 & 267 & 94.558 & & \\
Total & 35840.959 & 268 & & &
\end{tabular}

a. Predictors: (Constant), Social Intelligence.

b. Dependent Variable: Intercultural sensitivity.

Coefficients $^{\mathrm{a}}$

\begin{tabular}{llllll}
\hline Model & \multicolumn{2}{l}{ Unstandardized Coefficients } & $\begin{array}{l}\text { Standardized } \\
\text { Coefficients }\end{array}$ & $\mathrm{t}$ & Sig. \\
\cline { 2 - 4 } & $\mathrm{B}$ & Std. Error & Beta & \\
\hline 1 (Constant) & 34.243 & 4.141 & .654 & 8.269 & .000 \\
$\begin{array}{l}\text { Communication } \\
\text { Competence }\end{array}$ & .804 & .057 & & 14.135 & .000 \\
\hline
\end{tabular}

a. Dependent Variable: Intercultural Sensitivity.

\section{Discussion}

\subsection{Level of Intercultural Sensitivity}

The findings show that on average the level of intercultural sensitivity of the international undergraduates participating the study was high $(X=92.29$ out of the 120 total score or $76.91 \%)$. This is probably because first, all of the participants were foreign students. Research has proven that personal experiences in a host country help develop intercultural sensitivity. Foreign students were reported with significantly higher levels of intercultural sensitivity than domestic students (McMurray, 2007; Lyttle et al., 2011; Chocce et al., 2015). Moreover, it was found that age was an influential factor affecting one's intercultural sensitivity (Del Villar, 2010). The participants of the present study were undergraduates whose ages ranged from 18-25. When people get older, they generally become more mature because "maturity comes with life experiences that generally lead to better understanding and tolerance for differences" (Del Villar, 2010). Third, since the participants were 
foreign undergraduates in international schools, they had more exposure and opportunity to use the language (English as an international language) in the host country and in classrooms (in which most students had different demographic backgrounds) than the local students. Therefore, it can be concluded that another factor that more or less contributed to their high level of intercultural sensitivity in this study was their English language competence enabling them to interact more with their classmates from different cultures. Aydogan and Akbarov (2014) found that language communication skills significantly correlated with almost all constructs of intercultural sensitivity. Surveys done by Olson and Kroeger (2001), and Sizoo et al. (2004) concluded that foreign language ability is a variable promoting intercultural sensitivity.

These findings, however, cannot be claimed as accurate or generalized because the high level of intercultural sensitivity of the international undergraduates of the present study was based solely on a self-reported measure (intercultural sensitivity scale). It is clear that even though there are a number of advantages in self-reports (Lucas \& Baird, 2006; Paulhus \& Vazire, 2007) that have made the self-reports the most preferred method to assess personality traits (Vazire, 2006; Robins et al., 2007), there are also a number of potential weaknesses when using self-reports to measure psychological constructs (McDonald, 2008). A crucial problem concerns inaccuracy of its findings caused by errors on the part of the respondents. Self-reports leave a lot of room for 'response biases' (Moskowitz, 1986) producing the so-called 'socially desirable response' to present themselves in a more favorable light, even though their responses do not reflect how they actually behave or think (Paulhus, 1991). Therefore, the findings in terms of the level of intercultural sensitivity of the international undergraduates of the present study cannot be considered accurate or generalized unless multiple methods are applied to triangulate the findings. Furthermore this could be the reason why extensive research on intercultural sensitivity using self-report measures has emphasized the investigation of predictive factors of intercultural sensitivity rather than the accurate level of intercultural sensitivity of the research participants.

\subsection{Correlations between Intercultural Sensitivity and Their Five Factors}

The present study found that all individual factors of intercultural sensitivity namely interaction engagement, interaction enjoyment, interaction attentiveness, interaction confidence, and respect for cultural differences, had a positive correlation with the total intercultural sensitivity scores: from most to least interaction engagement (.809), respect for cultural difference (.804), interaction enjoyment (.741), interaction confidence (.667) and interaction attentiveness (.557). The fact that all five of these factors had a high to moderate correlation with the total intercultural sensitivity score is simply because all the scale questions under each factor were constructed to assess intercultural sensitivity, which includes all five factors, and that each factor more or less plays its role toward the intercultural sensitivity level. In other words, the assessment would not be complete if it lacked a question in a particular factor. This can be explained in more details as follows:

According to Chen and Starosta (1997) intercultural sensitivity is the affective dimension of intercultural communication competence which includes six components: self-esteem, self-monitoring, open-mindedness, empathy, interaction involvement, and non-judgment. Therefore, interculturally sensitive persons are those who possess these six elements. Chen and Starosta's (2000) intercultural sensitivity scale was designed and constructed to assess the possession of these six elements. The scale's questions were labeled interaction engagement, respect for cultural differences, interaction confidence, interaction enjoyment, and interaction attentiveness, rather than simply six components.

\subsubsection{Interaction Engagement}

The fact that interaction engagement had the highest correlation (.809) to the total intercultural sensitivity score is probably because interaction involvement is fundamental to the human communication process (Cegala, 1984), while interculturally sensitive persons know how to "handle the procedural aspects of structuring and maintaining a conversation" (Spitzberg \& Cupach, 1984, p. 46).

\subsubsection{Respect for Cultural Differences}

The study showed that respect for cultural differences was the second factor that correlated highly with the total intercultural sensitivity score (.804). This is probably because interculturally sensitive persons are open-minded or willing to openly and appropriately explain themselves and accept other's explanations (Chen \& Starosta, 1997). They possess an internalized broadened concept of the world (Bennett, 1986), or understand and acknowledge other people's needs that makes them more adaptive to differences in culturally diverse situations (Yum, 1989) Therefore, those who are interculturally sensitive must be those who respect others' cultures. The lack of this factor causes intercultural communication failures. Consequently, high correlation was found between respect for cultural differences and intercultural sensitivity. 


\subsubsection{Interaction Enjoyment}

The third factor having a high correlation (.741) with the total intercultural sensitivity score was interaction enjoyment. This finding was well-supported by previous research proving that those who were interculturally sensitive were those who enjoyed themselves in intercultural interactions. Hart \& Burks (1972) explained that interculturally sensitive persons did not hastily jump to conclusions without having sufficient data in interactions (Hart \& Burks (1972), which allows the other party to be satisfied and happy that he/she has been actively listened to (Chen, 1997), and they themselves are also happy. Many types of enjoyment reported are, for example, that they enjoy interacting with people from different cultures (Randolph et al., 1977), enjoy increasing good working relations with others from different cultures (Fiedler et al., 1971), and enjoy one's duties in another culture (Gudykunst et al., 1977).

\subsubsection{Interaction Confidence}

The finding that interaction confidence had a significantly positive correlation with the total intercultural sensitivity score (.667) confirmed the importance of self-esteem regarding one's intercultural sensitivity as shown by extensive previous research. Self-esteem, conceptualized as having two dimensions: self-efficacy and self-worth (Gecas \& Schwalbe, 1986), is so influential regarding the development of intercultural sensitivity that it was included as one of Chen's (1997) six components of intercultural sensitivity. People with high self-esteem can motivate themselves by thinking they are powerful, strong, and good (Bandura, 1999). It was found that when individuals positively value themselves, they tend to contribute more to their interpersonal relationships (Kernis et al., 2000), which leads to successful interpersonal relationships (Sternberg \& Vroom, 2002).

Moreover, those with high self-esteem would not only feel confident in themselves but also feel accepted by others, regardless of success or failure (Baldwin et al., 2004). According to Foote and Cottrell (1955) culturally sensitive people usually show higher degrees of self-esteem because they have an optimistic outlook that instills confidence in interaction with others. In other words, they are likely to think well of others and to expect to be accepted by others (Hamachek, 1982).

\subsubsection{Interaction Attentiveness}

Similarly to interaction confidence, interaction attentiveness also had a moderately positive correlation with the total intercultural sensitivity score (.557). Interaction attentiveness refers to 'Empathy,' and 'Self-monitoring, two of Chen's (1997) six components of intercultural sensitivity. Those who are empathetic possess the characteristics of displaying identification, understanding and consideration to others while high self-monitoring persons are more attentive, other-oriented, and adaptable to diverse communication situations (Spitzberg \& Cupach, 1984). That interaction attentiveness has a significant positive correlation with intercultural sensitivity is also well-supported by previous theories and research.

Since empathy helps develop a mutual understanding leading to the establishment of an intercultural rapport (Barnlund, 1988), it has been recognized as a central component or the essence of intercultural sensitivity and enables a person to be competent in intercultural communication (Bennet, 1979; Yum, 1989).

The reason why interaction confidence and interaction attentiveness of the present study merely had a moderately positive correlation with intercultural sensitivity is probably because of the limitation of the study in terms of insufficient number of participants, the errors caused by self-report measures, or the fact that these two personal constructs, self-esteem and empathy, are probably too complicated to be assessed by only one research instrument or that an actual research-based self-esteem/empathy inventory is also needed.

4.3 Correlations between Intercultural Sensitivity and Demographic Factors (Gender, Nationality, School of Study, and Length of Stay in Other Cultures)

These correlations were examined aiming to find if or to what extent demographic factors favored intercultural sensitivity of international undergraduates in Thailand. The findings suggested that gender and school of study did not affect the participants' level of intercultural sensitivity unlike nationality and exposure to other cultures (length of stay).

\subsubsection{Gender}

The present study found no significant differences between male and female intercultural sensitivity mean scores $(\mathrm{M}=91.21, \mathrm{SD}=11.82$ and $\mathrm{M}=93.58, \mathrm{SD}=11.15$ respectively). This finding is in accordance with literature showing that there was no significant difference in intercultural sensitivity between males and females (McMurray, 2007; Del Villar, 2010; Margarethe, 2012; and Chocce et al, 2015). However, females seemed to insignificantly exhibit higher intercultural sensitivity than males in some or all of the intercultural Sensitivity 
Scale's factors. It is a long-standing belief that women are more caring, more people-oriented, and more empathic than men. According to Goleman (1998, p. 322) "women do tend to experience this spontaneous matching of feeling with others more than men do." A number of psychological studies have reported that in general women are more empathic than men (such as Eisenberg \& Lennon, 1983; Baron-Cohen \& Wheelwright, 2004). However, these studies also noted that female advantage in empathy is not absolute since it depends on the type of empathy measured and various contextual factors. This point is probably a reason supporting the different findings by Banos (2006) and Nanda (2013-2014) who reported that females had a significantly higher level of intercultural sensitivity than males and Del Villar (2010) who found that males did significantly better than females in intercultural sensitivity. With these conflicting results, it can be concluded that gender is an inconclusive factor with regard to intercultural sensitivity.

\subsubsection{School of Study}

It was found that the mean scores of intercultural sensitivity among participants from different schools of study namely Arts \& Humanities, Business, and others, were not significantly different. The findings came in line with previous research such as Chocce et al. (2015) that investigated the level of intercultural sensitivity between students from three different programs: Sciences, Business Administration, and Marketing. However, when many fields of study were included in a study, significantly different findings were reported. For example Del Villar (2010) investigated the level of intercultural sensitivity between students of 24 colleges and found significant differences between them. These inconsistent results may suggest factors contributed to intercultural sensitivity other than merely different fields of study such as program courses that provide ample opportunities to learn about other cultures. Year-level of research participants can also become an extraneous variable that deflects the findings. Surprisingly, students of the Asian Institute of Tourism (AIT) showed the lowest mean score of intercultural sensitivity between those from 24 colleges, but still within the moderate sensitivity level (Del Villar, 2010), and this was due to the fact that the students had not yet had the exposure and training.

\subsubsection{Nationality}

The findings revealed significant differences in the total intercultural sensitivity scores as well as all constructs/factors of intercultural sensitivity between the Chinese and American undergraduates as illustrated in Table 4.7. This showed that the American participants had a higher level of intercultural sensitivity than the Chinese's: $98.02,81.68 \%$ (very high) and $82.40,68.67 \%$ (high) respectively. Despite these findings, it cannot be concluded that nationality significantly influenced the intercultural sensitivity.

Since the researcher did not find any literature that showed a comparison between Chinese and American university students' levels of intercultural sensitivity, the fact that the American participants significantly gained higher score might be influenced by other factors rather than simply nationality. For example, the American students had much fewer language constraints during intercultural communication than Chinese students who were not native English speakers. Therefore, it is suggested that the effect of nationality on intercultural sensitivity needs further research.

\subsubsection{Exposure to Other Cultures: Length of Stay}

The findings of the present study has confirmed that exposure to other cultures does influence intercultural sensitivity to some extent. Interestingly, it was not always found that the more exposure to other cultures, the higher level of intercultural sensitivity, as extensively reported by previous research (Olson \& Kroeger, 2001; Peng et al., 2005; Anderson et al., 2006; McMurray, 2007; Del Villar, 2010). According to the results of the present study, those with 1-4 years of exposure had similar levels of intercultural sensitivity with no significant differences. However, those with 3-4 years of exposure to other cultures had significantly lower mean scores of the total intercultural sensitivity, interaction engagement, and respect for cultural differences than those with less than 1 year. This is consistent with results from previous research reporting that exposure to other cultures did not contribute significantly to intercultural sensitivity (Taylor \& Henao, 2006; Fabregas et al., 2012; Chocce, 2015). Owing to this contradiction, more in-depth research is needed about exposure to other cultures as an influential factor toward intercultural sensitivity. This is because a self-report on merely length of stay abroad cannot completely guarantee the participants' actual intercultural experiences. There are also many other factors relating to exposure to other cultures such as language proficiency or lack of language proficiency resulting in avoiding contact with other cultures that will affect learning about new cultures (Gudykunst, 1979). Moreover, it can also be affected by number of countries visited, number of foreign friends, frequency of communication (Del Villar, 2010), or even race and ethnicity that affects willingness to communicate (Medina, 2004); Jackson et al., 2000; Dong et al., 2008; Bahk \& Jandt, 2008).

\subsection{Predictive Factors of Levels of Intercultural Sensitivity}


Two independent variables investigated as to whether they could predict the level of intercultural sensitivity included communication competence and social intelligence. The findings showed that both communication competence and social intelligence were good predictors of intercultural sensitivity $(29.6 \%$ and $42.8 \%$ predictive ability respectively).

\subsubsection{Communication Competence}

The stepwise regression analysis on the relationship between communication competence and intercultural sensitivity showed .754 coefficient force (R square: .296). This means that communication competence had $29.6 \%$ predictive ability of intercultural sensitivity. There has been no study that the researcher could find using regression analysis to see if communication competence can predict intercultural sensitivity, but only a number of correlation studies to see the relationship between these two variables. These studies have proven that students' perception of their communication competence correlated in a significant and positive way with their intercultural sensitivity score (Peng et al., 2005; Banos, 2006; Dilbeck et al., 2009; De Villar, 2010; Aydogan \& Akbarow, 2014). Simply put, the students who perceived themselves as communicatively competent were also sensitive to other cultures. In contrast, those who reported least competence, scored significantly lower in intercultural sensitivity. The researcher could not find any correlation studies with the same objective that reported opposite findings. Thus, it can be noted that when a significant correlation is found between communication competence and intercultural sensitivity, communication competence probably has more or less a predictive ability toward intercultural sensitivity.

Furthermore, this present study has finally supported this possibility. Communication competence is "...an individual's perception of her or his own competence in communication across a variety of contexts" (McCroskey, 1984, 1997). It is different from communication proficiencies that refer to one's actual skills or ability to communicate, not to the perception. Communication proficiencies comprise communication competence, willingness to communicate, and intercultural communication apprehension (Del Villar, 2010). Regarding the result of this present study, it can be justified that communication competence can predict the level of one's intercultural sensitivity because whenever people see themselves as competent communicators, they are also more willing to engage in interaction with others and with less apprehension (McCrosky. 1997). This is a reason why it can be $29.6 \%$ predicted that those with high communication competence also become more sensitive during intercultural contacts and vice versa. This means communication competence (the predictor) explained $29.6 \%$ of variance of intercultural sensitivity and that there was $70.4 \%$ of unexplained variance predicted by other factors.

\subsubsection{Social Intelligence}

The stepwise regression analysis on the relationship between social intelligence and intercultural sensitivity showed .804 coefficient force (R square: .428). This means that social intelligence had $42.8 \%$ predictive ability for intercultural sensitivity. There has been no study that the researcher could find using regression analysis to see if social intelligence can predict intercultural sensitivity, but only some correlation studies between these two variables. For example, Dong et al. (2008) reported that intercultural sensitivity could be shaped by various factors, one of which was social intelligence which was found to be significantly correlated with intercultural sensitivity.

Since intercultural sensitivity, the affective aspect of intercultural communication competence, indicates the "development of a readiness to understand and appreciate cultural differences in intercultural communication" (Chen \& Starosta, 2003, p. 344), social intelligence or "the ability to act wisely in human relations" (Thorndike, 1920 , p. 228) or sometimes called 'people skills' has a great fundamental role to play towards a person's intercultural sensitivity. Interculturally sensitive individuals are those who are more satisfied with life because they enjoy interacting with people from different cultures (Sizoo et al., 2004). Chen (1997) pointed out that highly interculturally sensitive persons were those who can regulate their behavior, see others' points of view, sincerely and actively listen, and are responsive, perceptive, and attentive. Therefore, it can undoubtedly be $42.8 \%$ predicted that the more social intelligence individuals possess, the more interculurally sensitive they become and vice versa. This means social intelligence (the predictor) explained $42.8 \%$ of variance of intercultural sensitivity and that there was $57.2 \%$ of unexplained variance predicted by other factors.

\section{Conclusion}

The findings of the study suggest that both communication competence and social intelligence are significant predictors of intercultural sensitivity, and that social intelligence plays a more important role than communication competence. Moreover, it was interestingly found that the total variance after combining $29.6 \%$ of communication competence and $42.8 \%$ of social intelligence together was $72.4 \%$. This implies that both 
predictors are key factors toward one's development of intercultural sensitivity that powerfully and ultimately affect intercultural communication.

These findings have implied that social intelligence, communication competence, as well as some demographic factors including nationality and exposure to other cultures (length of stay), should be taken into serious consideration when designing an international program or international business curriculums, since one of the instructional goals is to increase sensitivity to the complexity of intercultural interactions. This is because these variables more or less affect students' intercultural sensitivity, which is widely accepted to be a predictor of intercultural effectiveness and is associated with the potential to exercise intercultural competence (Fabregas et al., 2012).

Regarding some limitations of the research itself, it is recommended the following for scholars and researchers who would like to replicate the study. First, local (international) undergraduates should be included. Second, nationality and exposure to other cultures which were found in the present study, having significant relationship with intercultural sensitivity should be investigated further if they have any predictive ability towards a gain in intercultural sensitivity. Last but not least, research instruments be used other than self-reports such as interviews and journals to help validate the findings.

\section{References}

Anderson, P., Lawton, L., Rexeisen, R., \& Hubbard, A. (2006). Short-term study abroad and intercultural sensitivity: A pilot study. International Journal of Intercultural Relations, 30, 457-469. http://dx.doi.org/10.1016/j.ijintrel.2005.10.004

Aydogan, H., \& Akbarov, A. (2014). Attitudes and intercultural sensitivity towards English language teaching. The International Journal of Social Sciences, 20, 50-61.

Bahk, M., \& Jandt, F. (2008). Explicit and implicit perceptions of non-white and interracial interaction reluctance in the United States. Human Communication, 11(3), 313-332.

Baldwin, M. W., Baccus, J. R., \& Fitzsimons, G. M. (2004). Self-esteem and the dual processing of interpersonal contingencies. Self and Identity, 3, 81-93. http://dx.doi.org/10.1080/13576500342000068

Banos, R. V. (2006). Intercultural sensitivity of teenagers: A study of educational necessities in Catalonia. Intercultural Communication Studies, 15(2).

Barnlund, D. C. (1988). Communication in a global village. In L. A. Samovar, \& R. E. Porter (Eds.), Intercultural communication: A reader. CA: Wadsworth.

Baron-Cohen, S., \& Wheelwright, S. (2004). The empathy quotient: An investigation of adults with Asperger syndrome or high-functioning autism and normal sex differences. Journal of Autism and Developmental Disorders, 34, 163-175. https://doi.org/10.1023/B:JADD.0000022607.19833.00

Bennett, M. J. (1979). Overcoming the golden rule: Sympathy and empathy. In D. Nimmo (Ed.), Communication Yearbook 3. Newbury Park: Sage.

Black, J. S., \& Mendenhall, M. (1990). Cross-cultural training effectiveness: A review and theory framework for future research. Academy of Management Review, 15(1), 113-136. http://dx.doi.org/10.5465/AMR.1990.11591834

Cegala, D. J. (1984). Affective and cognitive manifestations of interaction involvement during unstructured and $\begin{array}{lllll}\text { competitive interactions. } & \text { Communication }\end{array}$ http://dx.doi.org/10.1080/03637758409390205

Chen, G. M., \& Starosta, W. J. (1996). Intercultural communication competence: A synthesis. Communication Yearbook, 19, 353-383. http://dx.doi.org/10.1080/23808985.1996.11678935

Chen, G. M., \& Starosta, W. J. (1997a). A review of the concept of intercultural sensitivity. Human Communication, 1, 1-16.

Chen, G. M., \& Starosta, W. J. (1997b). Chinese conflict management and resolution: Overview and implications. Intercultural Communication Studies, 1, 1-16.

Chen, G. M., \& Starosta, W. J. (1998). Foundations of intercultural communication. Boston: Allyn and Bacon.

Chen, G. M., \& Starosta, W. J. (2000). The development and validation of the intercultural sensitivity scale. Human Communication, 3, 1-15. 
Chen, G. M., \& Starosta, W. J. (2003). Asian approaches to human communication: A dialogue. Intercultural Communication Studies, 12(4), 1-15.

Chocce, J., Johnson, D. A., \& Yossatorn, Y. (2015). Predictive factors of freshmen's intercultural sensitivity. International Journal of Information and Education Technology, 5(10), 778-782. http://dx.doi.org/10.7763/IJIET.2015.V5.610

Del Villar, C. P. (2010). How savvy are we?: Towards predicting intercultural sensitivity. Human Communication, 13(3), 197-215.

Dilbeck, K., McCroskey, J., Richmond, V., \& McCroskey, L. (2009). Self-perceived communication competence in the Thai culture. Journal of Intercultural Communication Research, 38, 1-7. http://dx.doi.org/10.1080/17475750903381598

Dong, Q., Koper, R. J., \& Collaco, C. M. (2008). Social intelligence, self-esteem, and intercultural communication sensitivity. Intercultural Communication Studies, 17(2): 162-172.

Eisenberg, N., \& Lennon, R. (1983). Sex differences in empathy and related capacities. Psychology Bulletin, 94, 100-131. http://dx.doi.org/10.1037/0033-2909.94.1.100

Fabregas, J. M. G., Kelsey, K. D., \& Robinson, S. J. (2012). Predicting intercultural sensitivity using demographic variables among college of agriculture undergraduate students. US-China Education Review, A8, 710-719.

Fiedler, F. E., Mitchell, T., \& Triandis, H. C. (1971). The culture assimilator: An approach to cross-cultural training. Journal of Applied Psychology, 55, 95-102. http://dx.doi.org/10.1037/h0030704

Foote, N. N., \& Cottrell, L. S. (1955). Identity and interpersonal competence: A new direction in family research. University of Chicago Press.

Franko, K. (2012). Intercultural communication-The effect of difference in everyday working environment of companies (from Germany, Switzerland, Austria) in Hungary. EconPapers[online]: 767-773. Retrieved from http://econpapers.repec.org

Fritz, W., Mollenberg, A., \& Chen, G. (2002). Measuring intercultural sensitivity in different cultural contexts. Intercultural Communication Studies, 11(2), 165-176.

Gecas, V., \& Schwalbe, M. L. (1986). Parental behavior and adolescent self-esteem. Journal of Marriage and the Family, 48, 37-46. https://doi.org/10.2307/352226

Goby, P. V. (2007). Business communication needs a multicultural perspective. Journal of Business and Technical Communication, 21(4), 425-437. https://doi.org/10.1177/1050651907304029

Goleman, D. (1998). Working with emotional intelligence. New York, NY: Bantam Books.

Gudykunst, W. B. (1979). Intercultural contact and attitude change: A review of literature and suggestions for future research. International and Intercultural Communication Annual, 4, 1-16.

Gudykunst, W. B., Hammer, M. R., \& Wiseman, R. (1977). An analysis of an integrated approach to cross-cultural training. International Journal of Intercultural Relations, 1 , 99-109. https://doi.org/10.1016/0147-1767(77)90045-1

Hamachek, D. E. (1982). Encounters with others: Interpersonal relationships and you. Holt, Rinehart, and Winston.

Hart, R. P., \& Burks, D. M. (1972). Rhetorical sensitivity and social interaction. Speech Monographs, 39, 75-91. http://dx.doi.org/10.1080/03637757209375742

Hooker, J. N. (2008). Cultural differences in business communication. In C. B. Paulston, S. F. Kiesling, \& E. S. Rangel (Eds.), Handbook of intercultural discourse and communication (pp. 389-407). Wiley.

Jackson, R., Shin, C., \& Wilson, K. (2000). The meaning of whiteness: Critical implications of communicating and negotiating race. World Communication, 29, 69-86.

Kernis, M., Golman, B., Paradise, A., Wheatman, S., \& Whitaker, D. (2000). Master of one's psychological domain" Not likely if one's self-esteem is unstable. Society for Personality and Social Psychology, 26, 1297-1305. https://doi.org/10.1177/0146167200262010

Klak, T., \& Martin, P. (2003). Do university-sponsored international cultural events help students to appreciate differences? International Journal of Intercultural Relations, 27, 445-465. http://dx.doi.org/10.1016/S0147-1767(03)00033-6 
Korhonen, K. (2004). Developing intercultural competence as part of professional qualifications: A training experiment. Journal of Intercultural Communication, 7 [online] Retrieved from http://www.immi.se/intercultural/

Lucas, R. E. \& Baird, B. M. (2006). Global self-assessment. In M. Eid, \& E. Diener (Eds.), Handbook of multimethod measurement in psychology (pp. 29-42). Washington, DC: American Psychological Association. https://doi.org/10.1037/11383-003

Lustig, M. W., \& Koester, J. (2003). Intercultural competence: Interpersonal communication across cultures. Boston: Pearson Education.

Lyttle, A., Barker, G., \& Cornwell, T. (2011). Adept through adaptation: Third culture individuals' interpersonal sensitivity. International Journal of Intercultural Relations, 35, 686-694. http://dx.doi.org/10.1016/j.ijintrel.2011.02.015

Mao, Y. (2010). Does culture matter? Relating intercultural communication sensitivity to conflict management styles, technology use, and organizational communication satisfaction in multinationals in China. Doctoral Dissertation. Retrieved from https://etd.ohiolink.edu/rws_etd/document/get/ohiou1281741620/inline

Margarethe, U., Hannes, H., \& Wiesinger, S. (2012). An analysis of the differences in business students' intercultural sensitivity in two degree programmes. Literacy Information and Computer Education Journal, 3(3), 667-674. https://doi.org/10.20533/licej.2040.2589.2012.0100

McCroskey, J. C. (1984). Communication competence: The elusive construct. In R. N. Bostrom (Ed.), Competence in communication. Beverly Hills, CA: Sage.

McCroskey, J. C. (1997). Willingness to communicate, communication apprehension, and self-perceived communication competence: Conceptualizations and perspectives. In J. A. Daly, J.C. McCroskey, J. Ayres, T. Hopf, \& D. M. Ayres (Eds.). Avoiding communication: Shyness, reticence, and communication apprehension (pp. 75-109). Cresskill, NJ: Hampton Press.

McCroskey, J. C., \& McCroskey, L. L. (1988). Self-report as an approach to measuring communication competence. Communication Research Reports, 5, 108-113. http://dx.doi.org/10.13072/midss.503

McDonald, J. D. (2008). Measuring personality constructs: The advantages and disadvantages of self-reports, informant reports and behavioral assessments. Enquire, 1(1), 1-17.

McMurray, A. A. (2007). Measuring intercultural sensitivity of international and domestic college students: The impact of international travel. Master's thesis, University of Florida.

Mendenhall, M., \& Oddou, G. (1985). The dimensions of expatriate acculturation: A review. Academy of Management Review, 10(1), 39-47. http://dx.doi.org/10.2307/258210

Moskowitz, D. S. (1986). Comparison of self-reports, reports by knowledgeable informants, and behavioral observation data. Journal of Personality, 54, 294-317. https://doi.org/10.1111/j.1467-6494.1986.tb00396.x

Nanda, S. (2013-2014). Are there gender differences in empathy? Undergraduate Journal of Psychology at Berkeley, 7, 32-38.

Olson, C. L., \& Kroeger, K. R. (2001). Global competency and intercultural sensitivity. Journal of Studies in International Education, 5(2), 116-137. https://doi.org/10.1177/102831530152003

Park, J. (2013). Multicultural experience and intercultural sensitivity among South Korean adolescents. Multicultural Education Review, 5(2), 108-138. http:/dx.doi.org/10.14328/MER.2013.09.30.108

Paulhus, D. L. (1991). Measurement and control of response bias. In J. P. Robinson, P. R. Shaver, \& L. S. Wrightsman (Eds.), Measures of personality and social psychological attitudes (pp. 17-59). New York: Academic Press. https://doi.org/10.1016/B978-0-12-590241-0.50006-X

Paulhus, D. L., \& Vazire, S. (2007). The self-report method. In R.W. Robins, R. C. Fraley, \& R. F. Krueger (Eds.), Handbook of research methods in personality psychology (pp. 224-239). New York: Guilford.

Peng, S. Y., Rangsipaht, S., \& Thaipakdee, S. (2005). Measuring intercultural sensitivity: A comparative study of ethnic Chinese and Thai nationals. Journal of Intercultural Communication Research, 34(2), 119-137.

Rahim, M. A. (1983). A measure of styles of handling interpersonal conflict. The Academy of Management Journal, 26(2), 368-376. http:/dx.doi.org/ 10.2307/255985

Randolph, G., Landis, D., \& Tzeng, O. (1977). The effects of time and practice upon culture assimilator training. $\begin{array}{lllll}\text { International Journal of Intercultural Relations, } & 1(4), & 105-119 .\end{array}$ 
https://doi.org/10.1016/0147-1767(77)90034-7

Robins, R. W., Fraley, R. C., \& Krueger, R. F. (2007). (Eds.), Handbook of research methods in personality psychology (pp. 224-239). New York: Guilford.

Silvera, D. H., Martinussen, M., \& Dahl, T.I. (2001). The Tromso Social Intelligence Scale, a self-report measure of social intelligence. Scandinavian Journal of Psychology, 42(4), 313-319. https://doi.org/10.1111/1467-9450.00242

Sizoo, S., Iskat, W., Plank, R., \& Serrie, H. (2004). Cross-cultural service encounters in the hospitality industry and the effect of intercultural sensitivity on employee performance. International Journal of Hospitality \& Tourism Administration, 4(2), 61-77. http://dx.doi.org/10.1300/J149v04n02_04

Spitzberg, B. H., \& Cupach, W. R. (1984). Interpersonal communication competence. CA: Sage Publications.

Sternberg, R. J., \& Vroom, V. H. (2002). The person versus the situation in leadership. Leadership Quarterly, 13, 301-323. https://doi.org/10.1016/S1048-9843(02)00101-7

Straffon, D. A. (2003). Assessing the intercultural sensitivity of high school students attending an international school. International Journal of Intercultural Relations, 27(4), 487-501. https://doi.org/10.1016/S0147-1767(03)00035-X

Taylor, J. A., \& Henao, V. M. (2006). Intercultural competence without international experience. Paper presented at the $9^{\text {th }}$ Annual ELT Conference, Bogota, Colombia, September 14-16, 2006.

The Office of the Higher Education Commission in Thailand (2014). Number of foreign students in Thai higher education institutions 2012. Retrieved from http://inter.mua.go.th/2015/05/number-of-foreign-students-in-thai-higher-education-institutions-2012/\#.V_C GAvmLTIU

Thorndike, E. L. (1920). Intelligence and its use. Harper's Magazine, 140, 227-235.

Triandis, H. C. (2006). Culture and conflict. In L. A. Samovar, R. E. Porter, \& E. R. McDaniel (Eds.), Intercultural Communication: A reader (pp. 22-31). Belmont, CA: Wadsworth.

Varner, I., \& Beamer, L. (2010). (5 $5^{\text {th }}$ ed.). Intercultural communication in the global workplace. Boston, MA: McGraw-Hill.

Vasilova, K., \& Baumgartner, F. (2005). Why is social intelligence difficult to measure? Retrieved from http://www.saske.sk/cas/archiv/4-2005/studia_vasilova-baumgartner.html

Vazire, S. (2006). Informant report: A cheap, fast, easy method for personality assessment. Journal of Research in Personality, 40, 472-481. http://dx.doi.org/10.1016/j.jrp.2005.03.003

Yu, T., \& Chen, G. (2008). Intercultural sensitivity and conflict management styles in cross-cultural organizational situations. Intercultural Communication Studies 17(2), 149-161.

Yum, J. O. (1989). Communication sensitivity and empathy in culturally diverse organizations. Paper presented at the $75^{\text {th }}$ Annual Conference of Speech Communication Association, San Francisco.

\section{Copyrights}

Copyright for this article is retained by the author(s), with first publication rights granted to the journal.

This is an open-access article distributed under the terms and conditions of the Creative Commons Attribution license (http://creativecommons.org/licenses/by/4.0/). 